
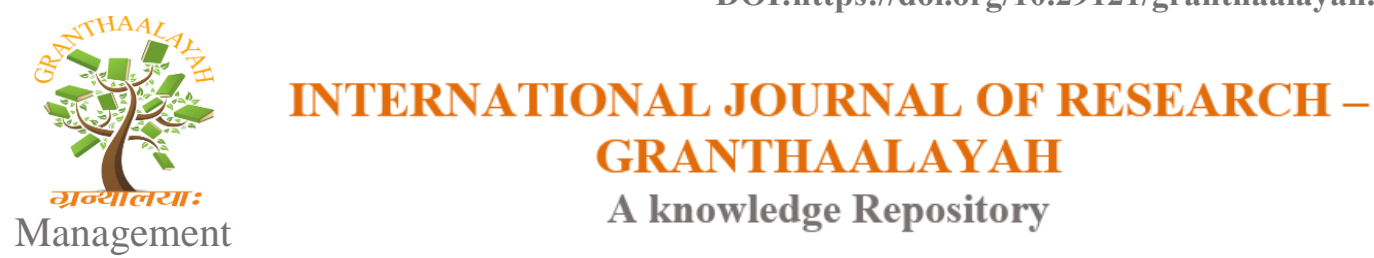

\title{
ANALYSIS OF TREND OF THE PRECIPITATION DATA: A CASE STUDY OF KANGRA DISTRICT, HIMACHAL PRADESH
}

\author{
Arijit Ganguly ${ }^{1}$, Ranjana Ray Chaudhuri ${ }^{2}$, Prateek Sharma ${ }^{3}$ \\ ${ }^{1}$ Environmental Studies \& Resources Management, Department of Natural Resources, TERI \\ University, Vasant-Kunj, New-Delhi-110070 \\ ${ }^{2}$ Associate Professor, Cocacola Department of Regional Studies, TERI University, Vasant-Kunj, \\ New-Delhi-110070 \\ ${ }^{3}$ Dean, Faculty of Applied Sciences, TERI University, Vasant-Kunj, New-Delhi-110070
}

\begin{abstract}
The current study is carried out to determine the potential trend of rainfall and assess its significance in Kangra district of Himachal Pradesh. Rainfall is a key characteristic of any watershed which plays a significant role in flood frequency, flood control studies and water planning and management. In this case study,mean monthly rainfall has been analysed to determine the variability in magnitude over the period 1950-2005. Trend in mean monthly precipitation data and mean seasonal trends are analysed using Mann-Kendall test and Sen's slope estimation for the data period 1950-2005. Analysis of monthly trend in precipitation shows negative trend for the months of July, August, September and October in all the rain gauge stations. However, the falling trend is significant for the month of August for Dharamshala(0.05 level of significance). Interestingly the month of June shows rising trend of rainfall in all the stations, however, at Dharamshala the trend is significant $(0.01$ level of significance). The winter rainfall in the month of January and February record decreasing trend, with Dera Gobipur and Kangra recording significant decreasing trend for the month of January at 0.01 level of significance and 0.05 level of significance respectively. Trend analysis for annual rainfall data shows significant negative trend for Dharamshala.
\end{abstract}

Keywords:

Trend analysis, Mann-Kendall Test, Sen's slope Estimator, mean annual and monthly rainfall.

Cite This Article: Arijit Ganguly, Ranjana Ray Chaudhuri, and Prateek Sharma, "ANALYSIS OF TREND OF THE PRECIPITATION DATA: A CASE STUDY OF KANGRA DISTRICT, HIMACHAL PRADESH" International Journal of Research - Granthaalayah, Vol. 3, No. 9(2015): 87-95. DOI: https://doi.org/10.29121/granthaalayah.v3.i9.2015.2948.

\section{INTRODUCTION}

Extreme events seem to be occurring with increasing frequency over the recent years. The focus on hydro-meteorological conditions is increasing for it holds the key for efficient management of water resources, flood management (Mondal et al, 2012). Any rise or fall in the annual average 
precipitation in a region leads to stress on annual average runoff flow in the region with consequent implication on planning of water resource, water allocation and overall integrated development of the watershed. Kangra district is a case in point for the average annual precipitation in the region is significantly higher than the annual average of the country. Many tributaries of the Indus river system have their source in the higher reaches of Himachal Pradesh and initial river flow is through the state, thus, any rise or fall in precipitation trends will have significant impact on basin management. Different studies world over on trend of climate and hydro-meteorological sciences point towards fluctuations in various parameters like precipitation, temperature leading to alternate cycles of flood and drought conditions (Kharmeshu,2012). A statistical study for the period 19181999 in Southern Italy show strong decrease in precipitation. Studies involving the Mediterranean region reveal decreasing precipitation in the already semi-arid region (Longobardi and Villani, 2010). Mondal et al. (2012) have analyzed the mean monthly precipitation data for the period1971 to 2010 along Birupa River in Orissa, India for possible trend in data. The result shows there is either non-significant increase or decrease in precipitation trend in the various months of the year, however, the amount of rainfall received every month has not been the same over the years and is seen to vary considerably between different years. Studies by Joshi and Pandey (2011) have observed no trend in annual precipitation over the entire Indian Territory and specific Indian regions for a study period of 100 years (1901-2000).

Increasing trend in temperature and decrease in precipitation has been found in the Lancang river basin, China in a 40 year period (Yunling and Yipping, 2005). Scientific evidences show there is a changing pattern of monsoonal period in India, and in present scenario it is difficult to predict the exact monsoon season (Parthasarathy et al, 1988; Ramanathan et al, 2005; Auffhammer et al, 2006). Together with implication of rise in global surface temperatures (IPCC,2007) and variability in precipitation due to climate change and anthropogenic causes, the need to study spatial and temporal variability in rainfall series in more detail cannot be over emphasised. Basistha et.al,(2008) conclude from their study on Uttarakhand state that the rainfall has decreased in this Himalayan state during the last century and the shift is sudden rather than gradual. The year of change is identified to be 1964 before which there was an increasing trend and after which there is a fall in trend (The period of study is 1901-1980).This is attributed to anthropogenic activities like conversion of marshy forests to cultivated land and settlement in the Terai region of Udham Singh Nagar district). Jain and Kumar, 2012 have pointed out in their study that there is decreasing trend of annual and monsoon rainfall in Shimla and this is significant at 95\% confidence level.

Time series of annual rainfall are studied statistically and trends are analysed both at annual and seasonal scale. There are various methods used to identify hydro-meteorological time series (Duhan and Pandey, 2013), they have conducted statistical analysis of long term spatial and temporal trends of precipitation during 1901-2002 in Madhya Pradesh, India. They identified that precipitation has decreased in the entire state and the most probable year of change is 1978. Trend analysis of rainfall time series includes determination of increasing and decreasing trend and magnitude of trend and its statistical significance (Jain and Kumar, 2012) by using parametric and non-parametric statistical methods. According to various studies on trend analysis, non-parametric methods are mainly used, Mann-Kendall test (Mann, 1945 and Kendall, 1975) is one of the best methods amongst them, which is preferred by various researchers (Douglas et al, 2000; Yue et al., 2003; Jain and Kumar, 2012). Mann- Kendall test is used for analysis and ascertains statistical significance by hypothesis test of hydrological variables (Yue et al, 2003). The advantages of the 
Mann-Kendall test are that it does not require that datasets follow normal distribution and show homogeneity in variance; transformations are not basically required if data already follows normal distribution, in skewed distribution greater power is achieved (Duhan and Pandey, 2013). Mann Kendall test also discusses about function of slope in the trend, coefficient of variation, and type of probability distribution (Yue et al, 2002a). Mann-Kendall test is used for trend analysis as it eliminates the effect of serial dependence on auto-correlated data which modifies the variance in datasets (Hamed and Rao, 1998). To analyse the magnitude of trend in the series, Sen's slope estimation, non-parametric,(Sen,1968) method is used. This method assumes the trend line is a linear function in the time series (Jain and Kumar, 2012). In Sen's slope model, the slope value shows the rise and fall of the variable (Jain and Kumar, 2012). Another advantage of using Sen's slope is that it is not affected when outliers and single data errors are present in the dataset (Salmi et al, 2002). Rupa Kumar et al, (1992) analyze trend for north-east India, north-west and northeast peninsular India and have found that the trend has decreased for monsoon period; they used 100 years dataset of this region.

The purpose of this study to assess the variability of precipitation in Kangra district, which is vulnerable as too little rain will affect the agriculture (the district economy is primarily dependent on agriculture) while too much rain will damage the infrastructure (the higher regions like Dharamshala are dependent on tourism). The major objective of this recent study is to determine and analyse the trend of the mean monthly precipitation and annual precipitation from data obtained from rain-gauge stations of Kangra District, Himachal Pradesh.

\section{STUDY AREA}

Kangra district is situated in the western part of Himachal Pradesh, India. It is bound by Chamba district in the North; Una, Hamirpur and Mandi districts in the South. The geographical area of the district is $5739 \mathrm{~km}^{2}$ which is $10.31 \%$ of the total area of the state. The coordinates of the district are $31^{\circ} 21^{\prime}$ to $32^{\circ} 59^{\prime} \mathrm{N}$ latitude and $75^{\circ} 47^{\prime} 55^{\prime \prime}$ to $77^{\circ} 45^{\prime}$ E longitude (Himachal Pradesh Government, 2009).

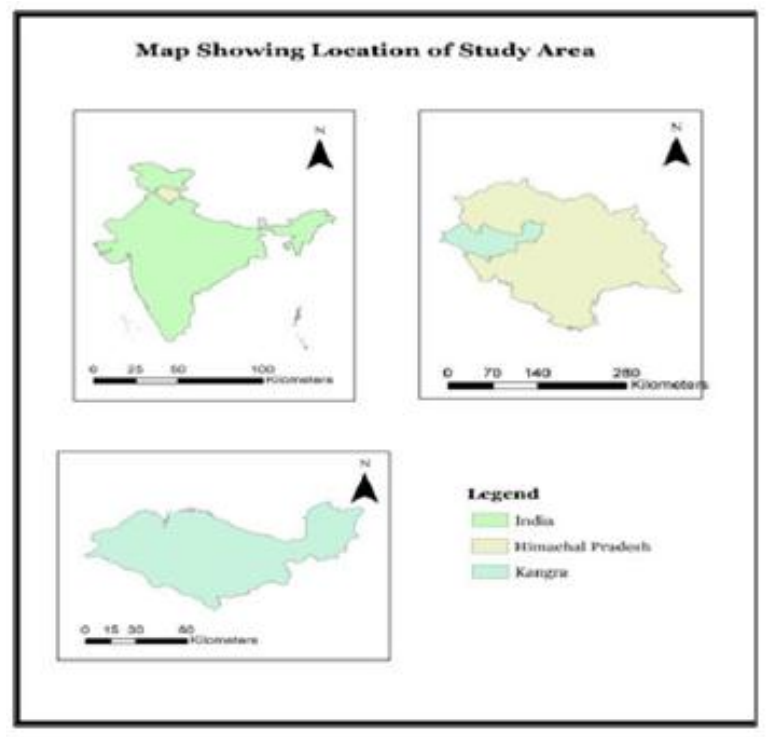

Figure 1: Study area of Kangra District 
River Beas is the main river basin of the district, agriculture is the major source of economy in this region (Himachal Pradesh, 2009). The seasonal variations in temperature and rainfall depend on the topographical features in the area. The annual temperature varies in this region from $0-40^{\circ} \mathrm{c}$. In summer it goes up to $38^{\circ} \mathrm{c}$; in the autumn season temperature varies between $7^{0}-16^{0} \mathrm{c}$; in spring temperature varies between $16^{0}-25^{\circ} \mathrm{c}$ while winters are severe with snowfall occurring in the northern part of district, notably in the hills (Dharamshala, Mcloedganj). Precipitation occurs throughout the year and the average annual precipitation of this region is around $1850 \mathrm{~mm}$ which is much higher the national average, about seventy percent of the rainfall occurs during the monsoon months. The annual precipitation varies between $1200-3000 \mathrm{~mm}$ within various parts of the district due to its unique topography. While regions like Dhera Gobipur in the foothills receives around $1200 \mathrm{~mm}$ of rainfall, places like Dharamshala and Palampur which are at high altitude receive $2000 \mathrm{~mm}-3000 \mathrm{~mm}$ annual precipitation.

\section{MATERIALS AND METHODS}

Average monthly average precipitation data for the period 1950-2005, (collected from NDC, IMD office Pune) for rain gauge stations in Kangra district are used. The methods of analyses adopted for study are Mann-Kendall Test and Sen's Slope estimator for trend detection. The data is studied for trend detection for Kangra district using four rain-gauge stations (Dehragopipur, Kangra, Dharamshala and Palampur) for the period of 1950 to 2005. The potential trend analysis is studied on monthly basis and annual basis for detection of variation of data.

The Mann-Kendall test used for trend analysis is a non-parametric method (Mann, 1945; Kendall, 1975). It is used for detection of statistically significant trend in variables like rainfall, temperature and streamflow. These are extremely important parameters for watershed modelling, studying catchment characteristics which are very important to determine water resources planning strategies in the long term for any region. The trend detection of the data is analyzed using the Mann-Kendall test (the significant trend of a data series). The Mann-Kendall Statistic S for trend is

$S=\sum_{i=1}^{n-1} \sum_{j=i+1}^{n} \operatorname{sgn}\left(x_{j}-x_{i}\right)$

Where the $x_{i}$ is the actual time data for a time series of $\mathrm{i}=1,2, \ldots \ldots \ldots \ldots, \mathrm{n}$.

$\operatorname{Sgn}=\left\{\begin{array}{cc}+1 & >\left(x_{j}-x_{i}\right) \\ 0 & =\left(x_{j}-x_{i}\right) \\ -1 & <\left(x_{j}-x_{i}\right)\end{array}\right.$

When the data $\mathrm{n} \geq 10$ the $\mathrm{S}$ statistic follows the normal distribution in a series with the mean of $\mathrm{E}(\mathrm{S})=0$ and the variance.

$\operatorname{Var}(S)=\frac{n(n-1)(2 n+5)-\sum_{i=1}^{m} t(t-1)(2 t+5)}{18}$

where $t_{i}$ are the ties of the sample time series. The test statistics $Z_{c}$ is as follows:

$Z_{c}=\left\{\begin{array}{cl}\frac{S-1}{\sqrt{\operatorname{Var}(S)}} & S>0 \\ 0 & S=0 \\ \frac{S+1}{\sqrt{\operatorname{Var}(S)}} & S<0\end{array}\right.$

Where $\mathrm{Z}_{\mathrm{c}}$ follows normal distribution, a positive $\mathrm{Z}_{\mathrm{c}}$ depicts an upward trend and negative $\mathrm{Z}_{\mathrm{c}}$ depicts downward trend for the period. At significance level $\alpha, Z_{c} \geq Z_{\alpha / 2}$, then the trend of the data is considered to be significant. The Mann Kendall test checks the null hypothesis of no trend to the 
alternate hypothesis of existence of trend in data. The above formula is valid when the number of observation $\mathrm{n} \geq 10$.

\section{Sen's Slope Estimation}

Sen's slope estimation (Sen, 1968) is another non-parametric method for trend analysis of precipitation data set. It is used to detect the magnitude of the trend.

$T_{i}=\frac{\left(x_{j}-x_{i}\right)}{j-k} \quad \mathrm{i}=1,2, \ldots \ldots \ldots \ldots \ldots . \mathrm{N}$

Where $\mathrm{x}_{\mathrm{j}} \mathrm{andx}_{\mathrm{k}}$ is the data values for $\mathrm{j}$ and $\mathrm{k}$ times of a period where $\mathrm{j}>\mathrm{k}$. the slope are estimated for each observation. Median is computed from N observations of the slope to estimate the Sen's Slope estimator

$Q_{i}=\left\{\begin{array}{cl}T_{\frac{N+1}{2}} & N \text { is Odd } \\ \frac{1}{2}\left(T_{\frac{N}{2}}+T_{\frac{N+1}{2}}\right) & N \text { is Even }\end{array}\right.$

When the N Slope observations are shown as Odd the Sen's Estimator is computed as $\mathrm{Q}_{\mathrm{med}}=$ $(\mathrm{N}+1) / 2$ and for Even times of observations the Slope estimate as $\mathrm{Q}_{\operatorname{med}}=[(\mathrm{N} / 2)+((\mathrm{N}+2) / 2)] / 2$. The two sided test is carried out at $100(1-\alpha) \%$ of confidence interval to obtain the true slope for nonparametric test in the series (Mondal et al, 2012). The positive or negative slope $Q_{i}$ is obtained as upward (increasing) or downward (decreasing) trend.

\section{RESULTS AND DISCUSSIONS}

The trend analysis of the precipitation data has been done using the data of precipitation of Kangra, Dehragopipur, Dharamshala and Palampur raingauge stations. Figure 2 shows the variability of the mean annual precipitation data for the entire period of study. There is decline in annual mean precipitation in the period 1950-2005, whether this will continue needs further research.
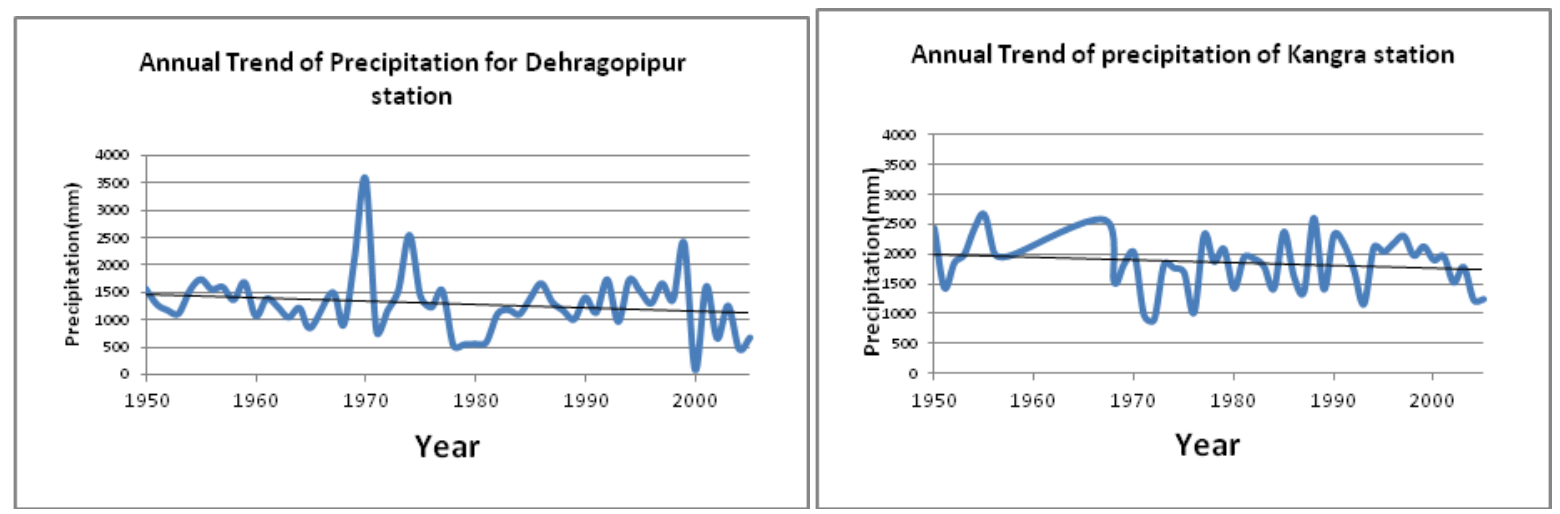

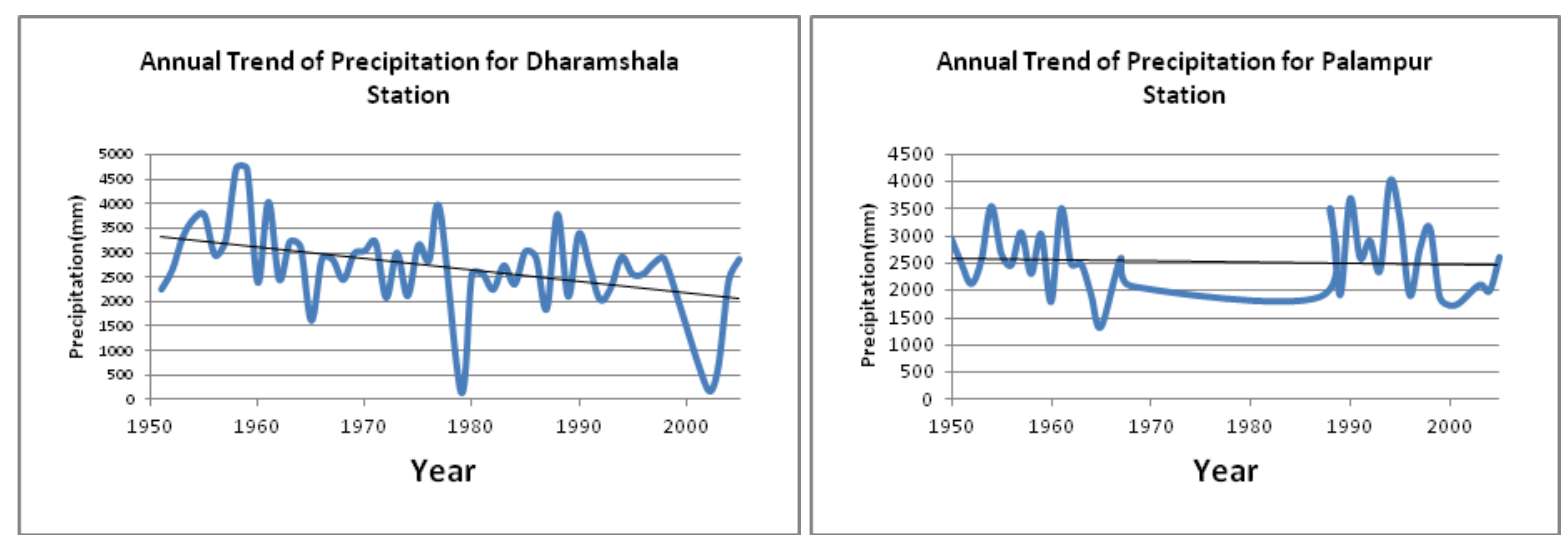

Figure 2: Annual Precipitation Data Variation for raingauge stations in Kangra District for 1950 to 2005

The results of Mann-Kendall test for trend analysis of data are presented in table 1 . The trend analysis has been done for all months of the year for all the stations under study in the district. The results of Mann-Kendall test for monthly precipitation data shows that there is a significant decrease in trend for the month of January for Dehragopipur and Kangra stations which are located at lower altitude in Kangra district while the other two stations located at high elevation have no significant trend for the month of January, even though the trend is falling across the entire district for the month of Jamuary. The first monsoon month of June shows a rise in trend across all stations with Dharamshala located at a high altitude, shows a significant increasing trend at 0.05 levels of significance. The following monsoon months of July, August and September show fall in trend across the entire district, however, these are not significant except for Dharamshala which shows a significant decrease in trend at 0.01 levels of significance for the month of August, Sen's slope magnitude is also large corresponding to the falling trend. The month of October too shows a falling trend across all stations for the data set used, however significant falling trend is found at 0.05 levels for Kangra station only. Though Palampur follows rainfall pattern similar to Dharamshala, no significant trend is found at 0.05 and 0.10 level of significance for any month.

Table 1: Trend analysis of Precipitation data 1950-2005 for Kangra region using Mann-Kendall $\operatorname{test}\left(\mathrm{Z}_{\mathrm{c}}\right)$ and Sen's Slope Estimator $\left(\mathrm{Q}_{\mathrm{i}}\right)$. Marks of * are for 0.01 level of significance and ${ }^{+}$with italics is for 0.05 level of significance.

\begin{tabular}{|c|c|c|c|c|c|c|c|c|}
\hline \multirow[t]{2}{*}{ Month } & \multicolumn{2}{|c|}{ Dehragopipur } & \multicolumn{2}{|c|}{ Kangra } & \multicolumn{2}{|c|}{ Dharamshala } & \multicolumn{2}{|c|}{ Palampur } \\
\hline & Z & $\mathbf{Q}$ & Z & $\mathbf{Q}$ & Z & $\mathbf{Q}$ & Z & $\mathbf{Q}$ \\
\hline JAN & $-1.67 *$ & -0.617 & $-2.16^{+}$ & -1.190 & -1.64 & -1.182 & -1.38 & -0.959 \\
\hline FEB & 1.57 & 0.740 & 1.15 & 0.656 & 0.83 & 0.621 & 0.87 & 0.534 \\
\hline MAR & -0.60 & -0.170 & -1.04 & -0.500 & 0.06 & 0.054 & 0.12 & 0.032 \\
\hline APR & 0.77 & 0.053 & 0.94 & 0.222 & 1.41 & 0.561 & 0.82 & 0.275 \\
\hline MAY & 1.04 & 0.163 & 1.35 & 0.388 & -0.09 & -0.031 & 0.02 & 0.000 \\
\hline JUN & 0.66 & 0.372 & 1.58 & 1.410 & $1.66^{*}$ & 1.472 & 1.30 & 1.880 \\
\hline JUL & -0.42 & -0.675 & -0.46 & -0.649 & -0.74 & -2.590 & -0.98 & -2.751 \\
\hline AUG & 0.07 & 0.250 & -1.40 & -1.778 & $-2.48^{+}$ & -5.156 & -0.39 & -0.868 \\
\hline SEP & -1.36 & -1.346 & -0.02 & -0.016 & -0.63 & -1.535 & -0.51 & -0.976 \\
\hline OCT & -1.45 & 0.000 & $-1.70 *$ & -0.090 & -1.02 & -0.361 & -1.10 & 0.000 \\
\hline
\end{tabular}




\begin{tabular}{lrrrrrrrr}
\hline NOV & -0.04 & 0.000 & 0.06 & 0.000 & -0.30 & 0.000 & -0.76 & 0.000 \\
\hline DEC & -0.04 & 0.000 & -0.15 & -0.171 & -0.43 & -0.075 & -1.46 & -0.174 \\
\hline
\end{tabular}
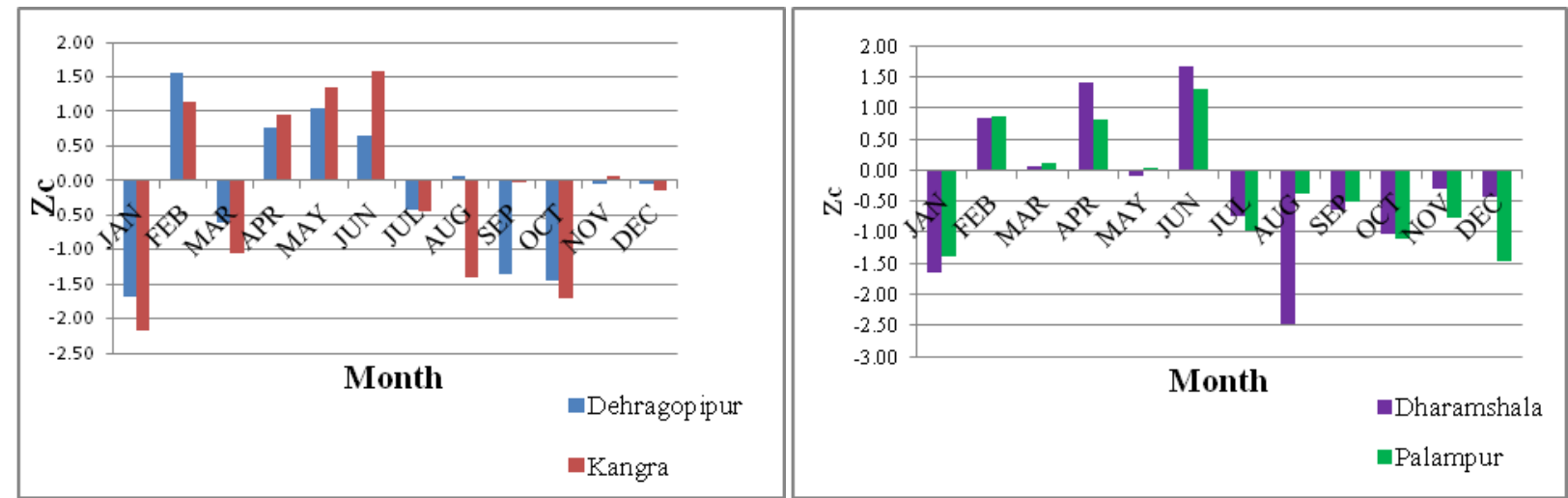

Figure 3: Trend analysis of average monthly precipitation of Kangra District raingauge stations 1950-2005

The study of data period 1994-2005 shows sharp decrease in trend in the month of August at 0.05 and 0.10 levels of significance and the magnitude is also high as can be seen from the Sen's slope estimator for the Dharamshala region. This is a cause for concern as Dharamshala used to record much higher rainfall than other parts of the Kangra district and the entire state. The falling trends in the monsoon months show that future detailed trend analysis needs to be done to assess temporal and spatial variation. The station wise variation in data does not necessarily reflect any significant change in trend in the overall values.

In order to determine the trend on annual scale analysis has been done for each station. The analysis of annual trend (Table 2 and figure 3 ) shows that it is closely related with the average monthly precipitation trend of the rain-gauge stations in Kangra district.

Table 2: Trend analysis of Seasonal Precipitation data 1950-2005 of Kangra Station using modified Mann-Kendall test $\left(\mathrm{Z}_{\mathrm{c}}\right)$ and Sen's Slope Estimator( $\left(\mathrm{Q}_{\mathrm{i}}\right)$. Marks of * are 0.05 level of significance and ${ }^{+}$italics letters are the significance level at 0.10 level of significance.

\begin{tabular}{lcc}
\hline Stations & Z & Q \\
\hline Dehragopipur & -1.22 & -4.500 \\
Kangra & -1.08 & -4.094 \\
Dharamshala & $-2.77^{+}$ & -16.235 \\
Palampur & -0.83 & -6.780 \\
\hline
\end{tabular}

The most significant annual trend is noticed for the Dharamshala station, where the decrease in trend is significant at 0.10 levels of significance. For the other stations an insignificant decrease of trend is found for this data set. At the district level there is an insignificant trend for the entire data set. 


\section{CONCLUSIONS \& RECOMMENDATIONS}

This study has been done for the period 1950-2005. The study area is unique as it has steep relief features at the higher altitudes (Dharamshala in particular) and numerous tributaries of river Beas flowing through the district. The amount of rainfall varies between different months in different years, with the variation extending across decades. From the trend analysis of precipitation data it can be concluded that even though insignificant change in precipitation pattern exists over the last few decades in most parts of the region, there is evidence of some change in precipitation trends in some monsoon months. The annual precipitation trend of data has also shown decreasing trend in the region with significant decrease in Dharamshala. This region has typically rich cultivable land and certain areas are showing increasing urbanization and land use changes. Further research may be taken up for the district to study the current agricultural practices, land use patterns, levels of erosion and sedimentation and levels of response to these parameters by the existing hydrological system in the area (runoff and its distribution). The Himalayan region is climate sensitive and maintains many fragile eco systems so more detailed study is recommended at watershed level and basin level as the complex terrain does not allow us to determine the extent of influence of each rain gauge station. Also daily precipitation data analysis will allow identification of different meteorological event types, we can assess the trend in that data set and utilise it to minimise effects of flash floods and landslides. Hill slopes, flora and fauna and human population residing in such areas are always vulnerable to such scenarios.

Distinct distinguishing trends may emerge and it is important to study this area in detail for it is a part of the river Beas basin. River Beas along with its many tributaries is reaching the Pong reservoir known for its rich wetlands which maintain bio diversity in addition to being an important source of water for irrigation and hydroelectric power supply downstream.

\section{ACKNOWLEDGEMENTS}

I acknowledge this study to my supervisor Ms Ranjana Roy Chaudhuri, Professor, TERI University and Prof Prateek Sharma, Dean, TERI University for giving opportunity and conducting the study and their valuable guidance. Also I thank to Dr P. K. Joshi, Head of the Department, TERI University for sharing his knowledge. I acknowledge to Indian Meterological Department and National Data Centre, Pune for giving the data for analysis in this study.

\section{REFERENCES}

[1] Auffhammer M, Ramanathan V, Vincent J R., 2006. Integrated model shows that atmospheric brown clouds and greenhouse gases have reduced rice harvests in India. Proc. National Academic Science, 103: 19668-72.

[2] Basistha A, Arya D.S., Goel N.K., 2008. Analysis of historical changes in rainfall in the Indian Himalayas, International Journal of Climatology, 29:555-572.

[3] Douglas E B, Vogel R M, Knoll C N., 2000. Trends in floods and low flows in the United States: impact of serial correlation. Journal of Hydrology, 240: 90-105.

[4] Duhan D, Pandey A., 2013. Statistical Analysis of long term spatial and temporal trends of precipitation during 1901-2002 at Madhya Pradesh, India Atmospheric research, Elsevier, 122: 136-49. 
[5] Government of Himachal Pradesh. 2009. District Human Developmental Report, Kangra, Planning Commission, Government of India, Planning Department, Himachal Pradesh, Department of Agricultural Economics, CSK Himachal Pradesh Agricultural University, Kangra. http://hpplanning.nic.in/HDR-Kangra.pdf. Access Date: 6th July, 2013.

[6] Hamed K H, Rao A R. 1998.A modified Mann-Kendall trend test for autocorrelated data. Journal of Hydrology, 204: 182-96.

[7] IPCC. 2007. Climate change 2007, climate change impacts, adaptation and vulnerability. Working Group II contribution to the Intergovernmental Panel on Climate Change Fourth Assessment Report. Summary for policymakers, 23.

[8] Jain S K, Kumar V. 2012.Trend analysis of rainfall and temperature data for India. Current Science, 102 (1): 37-49.

[9] Joshi M K, Pandey A C. 2011. Trend and spectral analysis of precipitation over India during 1901-2000.Journal of Geophysical Research.116. http://dx.doi.org/10.1029/2010JD014966. Access date: 18th June, 2013.

[10] Kendall M G. 1975.Rank correlation methods. Charles Griffin, London, 4: 202.

[11] Kharmeshu N. 2012. Trend detection in annual temperature and precipitation using MannKendall test-a case study to assess climate change on select states in North-eastern United States. Department of Earth and Environmental Sciences, University of Pennsylvania: 1 24.

[12] Longobardi A, Villani P. 2010. Trend analysis of annual and seasonal rainfall time series in the Mediterranean area. International Journal for Climatology, 30: 1538-46.

[13] Mann H B. 1945.Non-parametric test against trend.Econometrica, 13: 245-59.

[14] Mondal A, Kundu S, Mukhopadhyay A.2012. Rainfall trend analysis by Mann-Kendall Test: A Case Study of North-Eastern Part of Cuttack District, Orissa. International Journal of Geology, Earth and Environmental Sciences, ISSN:2277-2081, 2(1): 70-8.

[15] Parthasarathy B, Munot A, Kothawale D. 1988. Regression model for estimation of Indian food grain production from summer monsoon rainfall. Agriculture Forest Meteorology, 42: 167-82.

[16] Ramanathan Vet al. 2005.Atmospheric brown clouds: impacts on South Asian climate and hydrological cycle. Proc. National Academic Science, 102: 5326-33.

[17] Rupa Kumar K., Pant G B, Parthasarathy B, Sontakke N A. 1992. Spatial and sub seasonal patterns of the long term trends of Indian summer monsoon rainfall. International Journal of Climatology, 12: 257-268.

[18] Salmi T, Määttä A, Anttila P, Ruoho-Airola T, Amnell T. 2002.Detecting Trends of Annual Values of Atmospheric Pollutants by the Mann-Kendall Test and Sen's Slope Estimates The Excel Template Application Makesens. Finnish Meteorological Institute Publications on Air Quality No. 31, Helsinki, Finland: 1-35.

[19] Sen P K. 1968. Estimates of the regression coefficient based on Kendall's tau. Journal of the American Statistical Association, 63: 1379-89.

[20] Yue S, Pilon P, Cavadias G. 2002a. Power of the Mann-Kendall and Spearman's rho tests for detecting monotonic trends in hydrological series. Journal of Hydrology, 259: 254-71.

[21] Yue S, Pilon P, Phinney B. 2003. Canadian stream flow trend detection: impacts of serial and cross-correlation. Hydrological Science Journal, 48(1): 51-63.

[22] Yunling H, Yiping Z. 2005. Climate change from 1960 to 2000 in the Lancang River Valley, China. Mountain Research and Development 25 (4): 341-8. 